\title{
Analysis of the Low Temperature Fluorescence and Phosphorescence Spectra of $p$-Difluorobenzene
}

\author{
A. F. Childs, T. M. DunN, AND A. H. Francis \\ Department of Chemistry, University of Michigan, Ann Arbor, Michigan 48109
}

\begin{abstract}
The low temperature fluorescence spectra $(4.2 \mathrm{~K})$ of solid solutions of $p$-difluorobenzene- $h_{4}$ $\left(p \mathrm{DFB}-h_{4}\right)$ and $-d_{4}$ have been recorded and analyzed. The absence of fluorescence from vibrationally excited states at $4.2 \mathrm{~K}$ eliminates the sequence and "hot band" structure which complicate the analysis of the vapor fluorescence spectrum. On the basis of a comparison of our vibrational analysis with those published for the vapor phase fluorescence, several incorrect assignments in the latter have been identified. The high resolution and lack of spectral congestion obtained in the low temperature matrix isolated fluorescence spectra also allowed additional vibrational assignments to be made. These results are of added importance because of the extensive use which has been made of $p$ DFB for radiationless relaxation studies in the vapor phase. The phosphorescence spectrum of crystalline $p$ DFB- $h_{4}$ was observed with sufficient intensity to locate the electronic origin to make several vibrational assignments. Additionally, the zero-field splitting of the first triplet excited state was measured by optically detected magnetic resonance techniques.
\end{abstract}

\section{INTRODUCTION}

para-Difluorobenzene has been the subject of frequent spectroscopic investigation over the last 30 years because of its stability, large fluorescence quantum yield, and manageable number of degrees of freedom. Previous studies have concentrated on the electronic absorption and fluorescence spectrum of $p$ DFB in the vapor phase. The most recent published analysis of the vapor phase electronic spectrum is that by Cooper (3), but there is also an unpublished reanalysis by Zimmerman and Dunn (4). Recently, $p$ DFB has been employed in a number of studies of intermolecular and intramolecular vibrational energy redistribution in the vapor phase $(12-19)$. In these investigations, the dependence of the fluorescence quantum yield and the nonradiative lifetime upon the vibrational quantum state of the emitting level has been obtained. These results have substantially been compared with theoretical calculations based on different models for nonradiative relaxation in polyatomic molecules $(12-15,17,18)$. The theory predicts a dependence of the nonradiative relaxation rate on the "excess vibrational energy" in the excited electronic state in qualitative agreement with the experimental results. Comparison of theory and experiment requires a detailed vibrational analysis of the absorption and fluorescence spectra and researchers have generally referred to those previously published by Cooper (vide infra).

The low temperature $(4.2 \mathrm{~K})$ emission spectrum of $p D F B$ is simpler than that of the vapor phase. This is principally due to the absence of sequence and hot band structure. While the loss of sequence and hot band structure removes significant useful information from the spectrum regarding the changes in the electronic potential 
surface between the ground and excited electronic state, the simplification of the spectrum makes the assignment of the gross vibronic features observed far easier. Because of the low temperature employed, we may be completely certain that all features observed in the spectrum correspond to ground state fundamentals, their overtones, or combination bands. The narrow-line spectrum obtained from a correctly chosen low temperature matrix is largely free of phonon side-band structure.

Our study of the low temperature fluorescence spectra of $p$ DFB- $h_{4} /$ hexane solid solutions reveals several misassignments of the vapor phase fluorescence and resolves some conflicting assignments. Additionally, due to the simplicity of the low temperature fluorescence spectrum, it has been possible to make several additional assignments of vibrational features. When the vibrational assignments are :orrected, the agreement between experiment and theory for quantum yield and nonradiative lifetime is improved.

Use of the low temperature matrix technique does present some disadvantages for comparison with vapor phase spectra. In particular, the reduction in site symmetry may effect the selection rules for electric dipole radiation, resulting in the appearance of vibronic features not observed in the vapor phase. Although this does occur, the matrix induced features are extremely weak and are readily identified.

\section{EXPERIMENTAL DETAILS}

$p$ DFB- $h_{4}$ was obtained from Aldrich Chemical Company ( $>99 \%$ purity) and was used without further purification. $p D F B-d_{4}$ was prepared by deuterium exchange in $\mathrm{D}_{2} \mathrm{SO}_{4}$ and purified by repeated distillation. Mass spectral analysis of the DFB- $d_{4}$ sample showed that it contained 97 at.\% deuterium and $94 \% p D F B-d_{4}$. Solutions of $10^{-4}$ molar $\mathrm{p} D F B$ in cyclohexane were prepared using Aldrich Gold Label cyclohexane. Solvent blanks yielded no detectable fluorescence. The sample solutions were contained in 4-mm-o.d. cylindrical quartz tubes which were cooled at a rate of $1-2 \mathrm{~K} / \mathrm{min}$ to $77 \mathrm{~K}$ and at a more rapid rate to the final temperature of $5 \mathrm{~K}$ in a Janis 10DT liquid helium cryostat. More rapid cooling to $77 \mathrm{~K}$ resulted in multiple site emission spectra due to inclusions of a high temperature metastable cubic phase in the low temperature monoclinic cyclohexane lattice $(20,21)$.

Emission was excited by the $2650-\AA$ line emission of a $1-\mathrm{kW}$ high pressure $\mathrm{Xe}-$ Hg lamp isolated with a Heath EU-700 grating monochromator. Emission was observed at $90^{\circ}$ to the direction of excitation and dispersed in the second order of a $1-\mathrm{m}$ Jarrell-Ash scanning monochromator. In this mode the effective band-pass of the monochromator is $1 \mathrm{~cm}^{-1}$. The strong fluorescence signal was detected with a cooled EMI 6256-RF photomultiplier tube in combination with an SSR 1105 photon counter. The fluorescence spectra were calibrated with an iron/neon hollow-cathode discharge lamp to an estimated accuracy of $\pm 1 \mathrm{~cm}^{-1}$. The weak phosphorescence spectra were recorded in a similar manner. However, lower signal levels resulted in greater uncertainty in band positions $\left( \pm 5 \mathrm{~cm}^{-1}\right)$. The apparatus and techniques used for optically detected magnetic resonance (ODMR) measurements has been described in detail previously (22).

\section{DISCUSSION}

The molecular symmetry of $p \mathrm{DFB}$ is $D_{2 h}$ ( $z$ parallel to the $F-F$ axis, $y$ in plane) in both the ground and first singlet excited states. The first spin-allowed electronic 
excitation is ${ }^{1} B_{2 \mathrm{u}} \leftrightarrow{ }^{1} A_{\mathrm{g}}$, which is derived from the forbidden ${ }^{1} B_{2 \mathrm{u}} \leftrightarrow{ }^{1} A_{1 \mathrm{~g}}\left(D_{6 h}\right)$ transition of benzene which, in turn, derives its intensity from the electronically allowed ${ }^{1} E_{1 \mathrm{u}} \leftrightarrow{ }^{1} A_{1 \mathrm{~g}}$ state. Since the ground state symmetry is preserved in the ${ }^{1} B_{2 \mathrm{u}}$ state, only the six totally symmetric normal modes are formally active in the ${ }^{1} B_{2 u} \rightarrow$ ${ }^{1} A_{\mathrm{g}}$ fluorescence spectrum.

Figure 1 displays the fluorescence spectra of $p$ DFB- $h_{4}$ and $-d_{4}$ in cyclohexane matrix at $4.2 \mathrm{~K}$. The vibrational assignments are annotated directly above the most prominent bands in the spectrum. The complete vibrational analyses of $p$ DFB- $h_{4}$ and $-d_{4}$ fluorescence are given in Tables I and II, respectively. The frequencies of the ground state normal modes used in the vibrational analyses are those found by Zimmerman and Dunn $((10)$, hereinafter referred to as $\mathrm{ZD})$, which are reproduced here in columns 1 and 2 of Table III. This list includes "hot band" frequencies obtained in the analysis

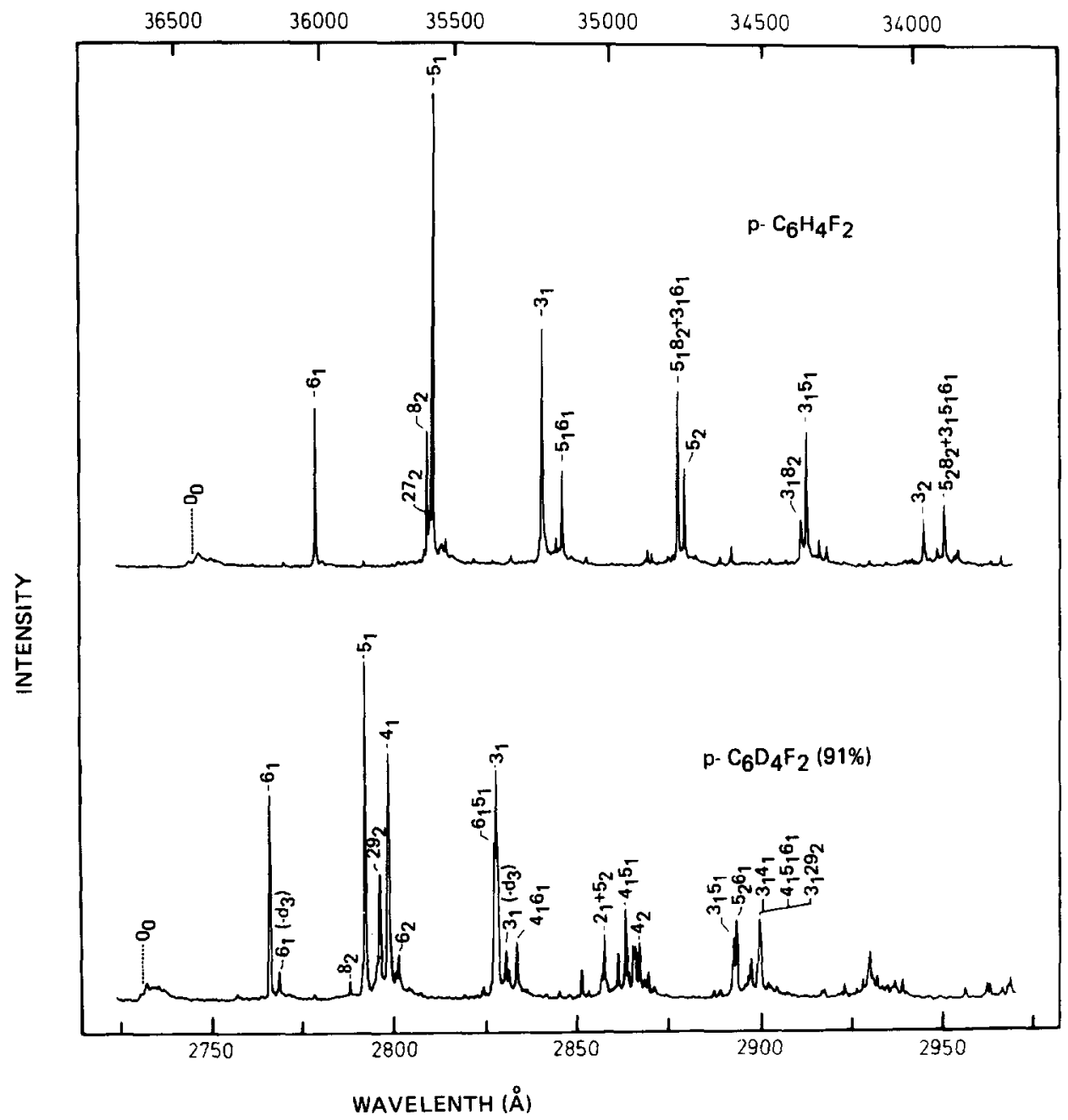

FIG. 1. Fluorescence of $p$ DFB- $h_{4}$ and $-d_{4}$ in cyclohexane matrix at $5 \mathrm{~K}$. 
TABLE I

${ }_{p}-\mathrm{C}_{6} \mathrm{H}_{4} \mathrm{~F}_{2}$ Fluorescence Frequencies and Assignments

\begin{tabular}{|c|c|c|c|}
\hline$v\left(+1 \mathrm{~cm}^{-1}\right)$ & $\begin{array}{l}\text { Relative } \\
\text { Intensity }(0-50)\end{array}$ & $\begin{array}{l}\mathrm{cm}^{-1} \text { from } \\
\text { origin }\end{array}$ & Assignment \\
\hline 36480 & -- & 0.0 & origin \\
\hline 36147 & 0.5 & 333 & $30_{2}$ \\
\hline 36026 & 16.0 & 454 & ${ }^{6} 1$ \\
\hline 35842 & 0.6 & 638 & $26_{1}$ \\
\hline 35648 & 1.7 & 832 & $28_{1}$ \\
\hline 35638 & 13.7 & 842 & $8_{2}$ \\
\hline 35628 & 5.4 & 852 & $27{ }_{2}$ \\
\hline 35620 & 46.9 & 860 & $5_{1}$ \\
\hline 35590 & 2.1 & 890 & (phonon S.B. of $5_{1}$ ) \\
\hline 35571 & 2.8 & 909 & $6_{2}$ \\
\hline 35344 & 1.1 & 1136 & $4_{1}$ \\
\hline 35227 & 23.7 & 1253 & $3_{1}$ \\
\hline 35184 & 2.9 & 1296 & $6_{1} 8_{2}$ \\
\hline 35165 & 9.6 & 1315 & $6_{1} 5_{1}^{2}$ \\
\hline 35065 & 0.8 & 1415 & $16_{2}$ \\
\hline 34886 & 1.4 & 1594 & ${ }^{9} 2$ \\
\hline 34870 & 1.1 & 1610 & ${ }^{2} 1$ \\
\hline 34815 & 0.9 & 1665 & $28_{2}$ \\
\hline 34805 & 0.9 & 1675 & ${ }^{8} 4$ \\
\hline 34779 & 17.6 & 1701 & $3_{1} 5_{1}+5_{1} 8_{2}$ \\
\hline 34752 & 9.8 & 1728 & $5_{2}$ \\
\hline 34719 & 0.6 & 1761 & $6_{2}^{5}{ }_{1}$ \\
\hline 34658 & 2.8 & 1822 & $15_{2}$ \\
\hline 34496 & 0.6 & 1984 & $<4_{1}^{5} 1$ \\
\hline 34386 & 4.5 & 2094 & ${ }^{3} 1^{8} 2$ \\
\hline 34369 & 13.3 & 2111 & $3_{1} 5_{1}$ \\
\hline 34327 & 2.5 & 2153 & $6_{1} 5_{1} 8_{2}+3_{1} 6_{2}$ \\
\hline 34302 & 1.9 & 2178 & $5_{2} 6_{1}\left(2 l_{2}\right)$ \\
\hline 34147 & 0.6 & 2333 & -- \\
\hline 34091 & 0.2 & 2389 & -- \\
\hline 33980 & 4.4 & 2500 & $3_{2}$ \\
\hline 33941 & 1.7 & 2539 & ${ }^{3} 1^{6}{ }_{1}^{8} 2$ \\
\hline 33918 & 5.9 & 2562 & ${ }^{3} 1^{5} 1^{6} 1$ \\
\hline 33891 & 0.7 & 2589 & $20_{2}$ \\
\hline 33878 & 1.4 & 2602 & $5_{3}$ \\
\hline
\end{tabular}

of the electronic spectrum by ZD (4). Table III also contains the vibrational analyses published by Gates $(8)$ in columns 3 and 4 , respectively.

\section{$p D F B-h_{4}$ Fluorescence}

The analysis of the $p \mathrm{DFB}-h_{4}$ fluorescence spectrum is at variance with the analyses of the vapor phase fluorescence in several important respects. Previous analyses of the vapor fluorescence have involved a ground state fundamental of $\sim 250 \mathrm{~cm}^{-1}$ in 
TABLE II

$p-C_{6} D_{4} F_{2}$ Fluorescence Frequencies and Assignments

\begin{tabular}{|c|c|c|c|}
\hline$v\left(\mathrm{~cm}^{-1} \pm 2\right)$ & $\begin{array}{l}\text { Relative } \\
\text { Intensity } \\
(0-50)\end{array}$ & $\begin{array}{l}\mathrm{cm}^{-1} \text { from } \\
\text { origin }\end{array}$ & Assignment \\
\hline 36622 & 2 & 0.0 & origin \\
\hline 36300 & 0.7 & 322 & $30_{2}$ \\
\hline 36171 & 26 & 451 & $\sigma_{1}$ \\
\hline 36135 & 3 & 487 & $\sigma_{1}\left(\right.$ pDFB- $\left.d_{3}\right)$ \\
\hline 36010 & 0.7 & 612 & $26_{1}$ or $9_{1}$ \\
\hline 35879 & 2 & 743 & $8_{2}\left(28_{1}\right)$ \\
\hline 35838 & 5 & 784 & $15_{1}$ \\
\hline 35831 & 43 & 791 & $5_{1}$ \\
\hline 35793 & 5 & 829 & -- \\
\hline 35785 & 15 & 837 & 292 \\
\hline 35760 & 31 & 862 & ${ }^{4} 1$ \\
\hline 35735 & 3 & 887 & - \\
\hline 35725 & 5 & 897 & $6_{2}$ \\
\hline 35431 & 1 & 1191 & $16_{2}$ \\
\hline 35386 & 20 & 1236 & $\sigma_{1} 5_{1}$ \\
\hline 35381 & 30 & 1241 & $3_{1}$ \\
\hline 35378 & 18 & 1244 & $9_{2}, 26_{2}$ \\
\hline 35344 & 6 & 1278 & $3_{1}\left(\mathrm{PDFB}-\mathrm{d}_{3}\right)$ \\
\hline 35332 & 4 & 1290 & ${ }^{6}{ }^{29} 2$ \\
\hline 35302 & 6 & 1320 & ${ }^{4} 1^{6} 1$ \\
\hline 35300 & 7 & 1322 & - \\
\hline 35192 & 1 & 1430 & $28_{2}$ \\
\hline 35113 & 3 & 1509 & $5_{1}{ }^{17} 7_{2}$ \\
\hline 35090 & 1 & 1532 & 241 \\
\hline 35042 & 2.5 & 1580 & ${ }^{15} 2$ \\
\hline 35035 & 8 & 1587 & $2_{1}+5_{2}$ \\
\hline 34986 & 5 & 1636 & ${ }^{5}{ }_{1}^{29}{ }_{2}$ \\
\hline 34958 & 11 & 1664 & $4_{1}^{5} 1$ \\
\hline 34950 & 2 & 1672 & ${ }^{29} 4$ \\
\hline 34933 & 7 & 1688 & ${ }^{3} 1^{6} 1$ \\
\hline 34927 & 6.5 & 1695 & -- \\
\hline 34924 & 5 & 1698 & $4_{1} 292$ \\
\hline 34911 & 8 & 1711 & $4_{2}$ \\
\hline 34893 & 2 & 1729 & -- \\
\hline 34881 & 3 & 1741 & -- \\
\hline 34857 & 2 & 1765 & -- \\
\hline 34660 & 1 & 1962 & -- \\
\hline 34642 & 1 & 1980 & -- \\
\hline 34600 & 8 & 2022 & $3_{1} 5_{1}$ \\
\hline 34592 & 11 & 2030 & ${ }^{5}{ }^{6} 1$ \\
\hline 34552 & 3 & 2070 & - \\
\hline 34546 & 5 & 2076 & ${ }^{5} 1_{1}^{6}{ }^{29}{ }_{2}+3_{1}{ }^{29} 2$ \\
\hline 34523 & 4 & 2099 & $3_{1}^{4} 1$ \\
\hline 34517 & 10 & 2105 & $4_{1}^{5} 1_{1}^{6}$ \\
\hline 34491 & 1 & 2131 & $61^{29} 4$ \\
\hline 34488 & 1 & 2134 & -- \\
\hline 34480 & 1 & 2142 & -- \\
\hline 34463 & 1 & 2159 & $4_{1}{ }^{6} 1^{29} 2$ \\
\hline
\end{tabular}


TABLE III

Ground State Vibrational Fundamental Frequencies of $\rho-\mathrm{C}_{6} \mathrm{H}_{4} \mathrm{~F}_{2}$ and $\rho-\mathrm{C}_{6} \mathrm{D}_{4} \mathrm{~F}_{2}$

\begin{tabular}{|c|c|c|c|c|c|}
\hline & $v_{i}$ & $\mathrm{C}_{6} \mathrm{H}_{4} \mathrm{~F}_{2}(\underline{10})$ & $\mathrm{C}_{6} \mathrm{D}_{4} \mathrm{~F}_{2}(\underline{\underline{10})}$ & $\mathrm{C}_{6} \mathrm{H}_{4} \mathrm{~F}_{2}(\underline{8})$ & $\mathrm{C}_{6} \mathrm{D}_{4} \mathrm{~F}_{2}(\underline{8})$ \\
\hline$a_{g}$ & $\begin{array}{l}1 \\
2 \\
3 \\
4 \\
5 \\
6\end{array}$ & $\begin{array}{l}3083 . \\
1615 . \\
1257.3 \\
1140 . \\
858.6 \\
449.8\end{array}$ & $\begin{array}{l}2309 . \\
1595 \\
1249.7 \\
866.9 \\
793.0 \\
446.3\end{array}$ & $\begin{array}{r}3084 \\
1617 \\
1245 \\
1142 \\
858 \\
451\end{array}$ & $\begin{array}{r}2313 \\
1595 \\
1229 \\
847 \\
780 \\
453\end{array}$ \\
\hline$\overline{a_{u}}$ & $\begin{array}{l}7 \\
8\end{array}$ & $\begin{array}{l}945 \\
420\end{array}$ & $\begin{array}{l}780 \\
367\end{array}$ & $\begin{array}{l}943 \\
405\end{array}$ & $=$ \\
\hline$\overline{b_{1 g}}$ & 9 & 800 & 614 & 800 & 614 \\
\hline$b_{1 u}$ & $\begin{array}{l}10 \\
11 \\
12 \\
13 \\
14\end{array}$ & $\begin{array}{r}3073 \\
1514 . \\
1228 . \\
1014 . \\
740 .\end{array}$ & $\begin{array}{r}2276 . \\
1440 . \\
1129 . \\
858 . \\
685 .\end{array}$ & $\begin{array}{r}3065 \\
1511 \\
1225 \\
1012 \\
737\end{array}$ & $\begin{array}{r}2277 \\
1435 \\
1130 \\
859 \\
685\end{array}$ \\
\hline$\overline{b_{2 g}}$ & $\begin{array}{l}15 \\
16 \\
17\end{array}$ & $\begin{array}{l}928 \\
692 \\
374 .\end{array}$ & $\begin{array}{l}780 \\
600 \\
358 .\end{array}$ & $\begin{array}{l}928 \\
692 \\
375\end{array}$ & $\begin{array}{l}780 \\
600 \\
366\end{array}$ \\
\hline $\mathrm{b}_{2 \mathrm{u}}$ & $\begin{array}{l}18 \\
19 \\
20 \\
21 \\
22\end{array}$ & $\begin{array}{r}3073 . \\
1633 . \\
1306 . \\
1085 . \\
348 .\end{array}$ & $\begin{array}{l}2307 . \\
1328 \\
1286 \\
802 \\
343.5\end{array}$ & $\begin{array}{r}3074 \\
1437 \\
1285 \\
1085 \\
350\end{array}$ & $\begin{array}{r}2310 \\
1328 \\
1287 \\
802 \\
348\end{array}$ \\
\hline$b_{3 g}$ & $\begin{array}{l}23 \\
24 \\
25 \\
26 \\
27\end{array}$ & $\begin{array}{c}3085 \\
1617 \\
1285 \\
635 \\
434\end{array}$ & $\begin{array}{c}2304 \\
1523 \\
1008 \\
614 \\
406\end{array}$ & $\begin{array}{r}3084 \\
1617 \\
1285 \\
635 \\
430\end{array}$ & $\begin{array}{r}2304 \\
1523 \\
1008 \\
614 \\
406\end{array}$ \\
\hline$\overline{b_{3 u}}$ & $\begin{array}{l}28 \\
29 \\
30\end{array}$ & $\begin{array}{l}835 . \\
505 . \\
157.5\end{array}$ & $\begin{array}{l}731 . \\
424 . \\
155.5\end{array}$ & $\begin{array}{l}833 \\
509 \\
170\end{array}$ & $\begin{array}{l}732 \\
422 \\
163\end{array}$ \\
\hline
\end{tabular}

Frequencies quoted correct to 1 decimal place are from vapour phase infrared, Raman, fluorescence and electronic absorption studies. Where the accuracy is only $\pm 1 \mathrm{~cm}^{-1}$, i.e., there is no precise measurement from the electronic spectrum, and the measurement is from the vapour phase, the number is followed by a period (e.g. 424.).

Out-of-plane vibrations are indicated by a bar over the vibration class.

many of the band assignments $(3,9)$. Initial concern about this assignment was raised by the absence of a Raman band at this frequency.

The matrix fluorescence spectrum does not show a band near $0-250 \mathrm{~cm}^{-1}$, thus eliminating any possibility of a ground state vibrational assignment. It is clear that this band is associated with an excited state fundamental and that bands involving this mode in the vapor phase fluorescence spectrum are part of the "hot band" spectrum. The band $0-250-\mathrm{cm}^{-1}$ is properly assigned as $8_{1}{ }^{1}$, the first member of the prominent $\nu_{8}\left(a_{v}\right)$ sequence (4). It should be noted that the prominent band 0-250 $\mathrm{cm}^{-1}$ and several related bands in the "hot band" spectrum have been treated as ground state fundamentals in studies of the nonradiative lifetime of $p \mathrm{DFB}-h_{4}$ single excited vibronic levels in the vapor phase. This error in assignment results in an error 
in the "excess vibrational energy" assigned to the level. When the assignment is corrected, the experimental value of the nonradiative lifetime is in far better agreement with theory (12).

Difficulty was encountered in locating the strongly reabsorbed electronic origin of the ${ }^{1} B_{2 \mathrm{u}} \rightarrow{ }^{1} A_{\mathrm{g}}$ transition in both the $p \mathrm{DFB}-h_{4}$ and $-d_{4}$ spectra. By adjusting the sample orientation to minimize the possibility of reabsorption, it was possible to observe the $p \mathrm{DFB}-h_{4}$ origin dircctly. The position of the $p \mathrm{DFB}-d_{4}$ origin was determined from the vibrational analysis.

The most interesting and controversial area of the spectrum is the region 800-900 $\mathrm{cm}^{-1}$ below the electronic origin. The major features include a strong band at 842 $\mathrm{cm}^{-1}$, a moderately intense band at $852 \mathrm{~cm}^{-1}$, and the strongest band in the spectrum at $860 \mathrm{~cm}^{-1}$. All the bands in this region have been reported as polarized in the Raman spectrum of $p$ DFB- $h_{4}$ and are undoubtedly in Fermi resonance. The 842and $860-\mathrm{cm}^{-1}$ bands were assigned as totally symmetric fundamentals by Ferguson et al. (2). Later, Stojiljkovic and Whiffen (5), in a study of a series of $p$-dihalogen benzenes, decided that a "more plausible assignment" for the $842-\mathrm{cm}^{-1}$ band $(854$ $\mathrm{cm}^{-1}$ in their study) is $2 \nu_{27}\left(b_{38}\right)$ in resonance with the $\nu_{5}\left(a_{8}\right) 858-\mathrm{cm}^{-1}$ fundamental. Gates et al. (8) asserted that this assignment is supported by the Teller-Redlich product rule analysis of the $p \mathrm{DFB}-h_{4}$ and $-d_{4}$ data. ZD $(10)$, however, reassigned the $842-\mathrm{cm}^{-1}$ band to $2 v_{8}\left(a_{\mathrm{u}}\right)$ which yields product rule agreement and is also consistent with the analysis of the prominent vapor phase sequences involving $\nu_{8}$. It is noted that $\nu_{8}$ is observed as a prominent vibronic origin in the two-photon ${ }^{1} B_{2 \mathrm{u}} \leftarrow{ }^{1} A_{1 \mathrm{~g}}$ transition investigated by Robey and Schlag (11). The low temperature fluorescence spectrum clearly shows three bands in this region, which can, at once, accommodate the $\mathrm{ZD} 2 \nu_{8}$ and Whiffen $2 v_{27}$ assignments, both deriving intensity from Fermi resonance with the $\nu_{5}$ fundamental.

It should be noted that combinations of the $842-\mathrm{cm}^{-1}$ band are necessary to complete the assignment of the spectrum. In this respect, the second harmonic behaves much as an $a_{\mathrm{g}}$ fundamental. In the $p \mathrm{DFB}-d_{4}$ spectrum, a band of equal relative intensity at $837 \mathrm{~cm}^{-1}$, assigned as the second harmonic of the non-totally symmetric $2 \nu_{29}\left(b_{3 u}\right)$, plays a similar role in forming combination bands. The importance of $2 \nu_{8}$ and $2 \nu_{29}$ in the spectra of $p$ DFB- $h_{4}$ and $-d_{4}$ must be attributed to Fermi resonance interactions with nearby totally symmetric modes.

Two non-totally symmetric modes, $\nu_{26}\left(b_{3 \mathrm{~g}}\right)$ and $\nu_{28}\left(b_{3 \mathrm{u}}\right)$ are active as vibronic origins in both the $p \mathrm{DFB}-h_{4}$ and $-d_{4}$ spectra. Although unexpected, it is difficult to justify another assignment of these bands. It is likely that they are induced by the lower than $D_{2 \mathrm{~h}}$ site symmetry of the matrix.

\section{pDFB- $d_{4}$ Fluorescence}

The presence of small amounts of $p \mathrm{DFB}-d_{3}$ complicates the vibronic analysis of the $p$ DFB- $d_{4}$ fluorescence spectrum. The bands at 487 and $1278 \mathrm{~cm}^{-1}$, each $36 \mathrm{~cm}^{-1}$ lower in energy than intense $\nu_{6}$ and $\nu_{3}$ fundamentals, are due to $p$ DFB- $d_{3}$ impurity. Both $\nu_{6}$ and $\nu_{3}$ are nearly unaffected by deuterium substitution. The origin shift from $-d_{4}$ to $-h_{4}$ is $142 \mathrm{~cm}^{-1}$, or $35.5 \mathrm{~cm}^{-1}$ per deuterium. This places the $p$ DFB- $d_{3}$ origin at approximately $36586 \mathrm{~cm}^{-1}$ and $\nu_{6}$ and $\nu_{3}$ at 487 and $1277 \mathrm{~cm}^{-1}$ with respect to 
the $-d_{4}$ origin, in excellent agreement with the observed band positions. The other $-d_{3}$ bands which may be present are more difficult to identify because their frequencies are significantly affected by isotopic substitution.

The vibrational analysis of the region $0-800 \mathrm{~cm}^{-1}$ of the $-d_{4}$ spectrum presents more complications than that of $-h_{4}$. Previous studies of the vibrational spectrum of $p$ DFB- $d_{4}$ have been carried out by ZD (Table III and Ref. (10)) and Gates (Table III and Ref. (8)). As expected, there is considerable similarity between the low temperature fluorescence and the vapor phase Raman spectra, as both are dominated by $a_{\mathrm{g}}$ fundamentals. The Raman doublet at $862 / 867 \mathrm{~cm}^{-1}$ is also observed as a doublet band in the low temperature fluorescence spectrum. However, the Raman singlet at 792 $\mathrm{cm}^{-1}$ is observed as a doublet $791 / 793 \mathrm{~cm}^{-1}$ in the fluorescence spectrum. The Raman doublet at $841 \mathrm{~cm}^{-1}$ is present in the fluorescence spectrum. First observed by ZD (10), it was attributed by asymmetric rotor splitting; however, its persistence in the matrix isolated fluorescence spectrum requires an alternative assignment. Gates observed two polarized Raman bands at $828 / 867 \mathrm{~cm}^{-1}$ and used the average frequency for the value of the $a_{\mathrm{g}}$ fundamental $\nu_{5}$. ZD assigned the $862 / 867 \mathrm{~cm}^{-1}$ doublet to the $\nu_{5}\left(a_{\mathrm{g}}\right)$ and the single band at $841 \mathrm{~cm}^{-1}$ as $2 \nu_{29}$, an assignment also considered by Gates ( 8$)$.

There is a very well-resolved doublet in the fluorescence spectrum at $1236 / 1241$ $\mathrm{cm}^{-1}$ which corresponds to a feature in the $p D F B-d_{4}$ vapor phase Raman spectrum recorded by $\mathrm{ZD}(10)$. The $\nu_{5}+\nu_{6}$ combination band should be located here and is probably in Fermi resonance with $\nu_{3}$. Finally, the $30_{2}$ assignment in both $p D F B-h_{4}$ and $p \mathrm{DFB}-d_{4}$ is questionable. However, there is no obvious alternative. The fundamental is known to an accuracy of better than $0.5 \mathrm{~cm}^{-1}$ implying a large anharmonicity for the overtone which differs for each isomer.

\section{$p D F B-h_{4}$ Phosphorescence}

Phosphorescence $\left({ }^{3} B_{1 \mathrm{u}} \rightarrow{ }^{1} A_{\mathrm{g}}\right)$ from $p$ DFB- $h_{4}$ in cyclohexane matrix at $4.2 \mathrm{~K}$ could not be detected; however, it was possible to record a weak phosphorescence spectrum using the pure crystalline material. Phosphorescence from $p \mathrm{DFB}$, in either the vapor or condensed phase, has not been previously reported. The spectrum, shown in Fig. 2 , was recorded in detail sufficient to permit assignment of only the most intense features and location of the electronic origin. As in the phosphorescence spectra of $p$-dichlorobenzene ( $p \mathrm{DCB}$ ) and $p$-dibromobenzene ( $p \mathrm{DBB})$, the most prominent feature of the $p$ DFB phosphorescence spectrum is the $b_{2 \mathrm{~g}}\left(\nu_{17}\right) 375-\mathrm{cm}^{-1}$ progression. The two remaining $b_{2 \mathrm{~g}}$ fundamentals, $\left(\nu_{15}\right) 928 \mathrm{~cm}^{-1}$ and $\left(\nu_{16}\right) 692 \mathrm{~cm}^{-1}$, are also observed in the phosphorescence spectrum (Table IV).

The activity of the $b_{2 \mathrm{~g}}$ fundamentals in the phosphorescence spectrum is not unexpected. They are associated with phosphorescence from the $\tau_{y}$ spin sublevel of the ${ }^{3} B_{1 \mathrm{u}}$ state of overall (spin $\times$ orbit) symmetry $B_{3 \mathrm{u}}$. These transitions are, therefore, allowed by a vibronic mechanism of the Herzberg-Teller type and are polarized parallel to the allowed ${ }^{1} B_{1 \mathrm{u}} \leftrightarrow{ }^{1} A_{\mathrm{g}}$ transition. The totally symmetric fundamentals which appear in the phosphorescence spectrum of $p D F B$ are associated with either the $\tau_{y}$ or $\tau_{x}$ spin sublevel spectra and are expected to have a polarization perpendicular to that of the $b_{2 \mathrm{~g}}$ vibronic origins. 


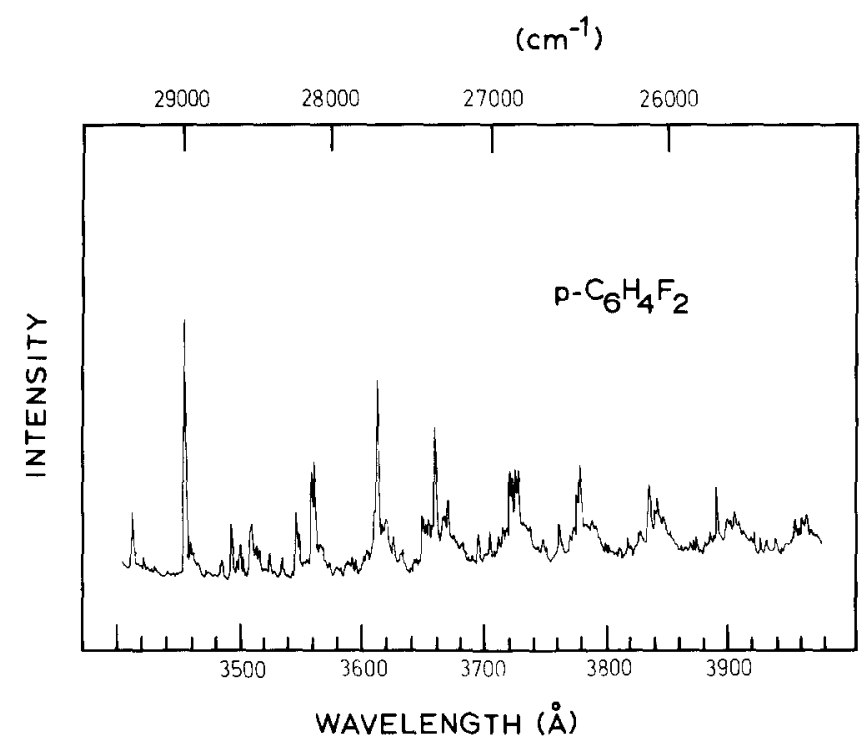

FIG. 2. Phosphorescence spectrum of crystalline $p \mathrm{DFB}-h_{4}$ at $5 \mathrm{~K}$.

Although the phosphorescence spectrum was extremely weak, it was possible to measure the zero-field splitting of the ${ }^{3} B_{1 \mathrm{u}}$ state using the optically detected magnetic resonance technique. The resonance frequencies obtained from the microwave spectrum of $p$ DFB monitoring the entire $p$ DFB phosphorescence spectrum are 2704.9 and $3517.8 \mathrm{MHz}$ which correspond to the $D+E\left(\tau_{x} \leftrightarrow \tau_{y}\right)$ and $D-E\left(\tau_{x} \leftrightarrow \tau_{z}\right)$ zero-field transitions, respectively. The $2 E\left(\tau_{z} \leftrightarrow \tau_{y}\right)$ transition is expected to be weak

TABLE IV

$p-\mathrm{C}_{6} \mathrm{H}_{4} \mathrm{~F}_{2}$ Phosphorescence Frequencies and Assignments

\begin{tabular}{lcc}
\hline$\nu\left( \pm 10 \mathrm{~cm}^{-1}\right)$ & $\begin{array}{l}\mathrm{cm}^{-1} \text { from } \\
\text { origin }\end{array}$ & Assignment \\
\hline 29283 & 0 & origin \\
28912 & 371 & $17_{1}$ \\
28595 & 688 & $16_{1}$ \\
28540 & 743 & $17_{2}$ \\
28342 & 941 & $15_{1}$ \\
28135 & 1148 & $17_{3}$ \\
28054 & 1229 & 31 \\
27665 & 1618 & $17_{1} 3_{1}$ \\
27648 & 1635 & 21 \\
27350 & 1933 & $16_{1} 3_{1}$ \\
27288 & 1995 & $17_{1} 2_{1}$ \\
26810 & 2473 & $215_{1}$ \\
26793 & 2490 & $3_{2}$ \\
\hline
\end{tabular}


TABLE V

${ }^{3} B_{14}$ Electronic Origin and Zero-Field Splitting Parameters for $p$-Dihalogenated Benzenes

\begin{tabular}{lllll}
\hline origin & Compound & D (GHz) & E (GHz) & Reference \\
\hline 29283 & p-Difluorobenzene & +3.111 & -0.406 & \\
$27410^{+}$ & p-Dichlorobenzene & +4.3235 & -0.6845 & $(23)$ \\
$27318^{+}$ & p-Dibromobenzene & +8.055 & -1.800 & (23) \\
\hline
\end{tabular}

+ p-xylene lattice

$(23,24)$ and could not be observed. The values of the fine structure parameters $D$ and $E$ computed from the observed zero-field splittings are reported in Table $\mathrm{V}$, where they are compared with the previously reported values of these parameters for other members of the $p$-dihalogen benzene family. The magnitude of $E$ is directly related to the deviation from axial symmetry about the $x$ axis (normal to the molecular plane); $D$ is directly related to spin-dipolar interactions along the $D$ axis. However, it is likely that the value of $D$ is affected by spin-orbit coupling, making the detailed comparison between different members of the family less meaningful.

\section{CONCLUSION}

The low temperature, narrow-line fluorescence spectra of $p$ DFB- $h_{4}$ and $-d_{4}$ in cyclohexane matrices have been recorded and vibrationally analyzed. The simplicity of these spectra, relative to vapor phase fluorescence, has permitted elimination of ambiguities and correction of misassignments of the vapor phase fluorescence spectrum.

The weak phosphorescence of $p \mathrm{DFB}-h_{4}$ has been observed and partially vibrationally analyzed. The triplet state fine structure parameters measured for $p \mathrm{DFB}$ complete the set of measurements for the p-dihalogen benzenes.

\section{ACKNOWLEDGMENTS}

The authors thank Anna Kalynych for assistance in measurements of spectra. This work was supported by the donors of the Petroleum Research Fund administered by the American Chemical Society.

RECEIVED: May 5, 1983

\section{REFERENCES}

1. A. H. Delsemme, J. Chem. Phys. 18, 1680 (1950).

2. E. E. Ferguson, R. L. Hudson, J. R. Nielsen, And D. D. Smith, I. Chem. Phys. 21, 1457-1463 (1953).

3. C. D. COOPER, J. Chem. Phys. 22, 503-510 (1954).

4. R. L. ZIMMERMAN AND T. M. DUNN, to be published.

5. A. STOJIKJKoviC AND D. H. WhIFFeN, Spectrochim Acta 12, 47-56 (1958).

6. E. W. SCHMID, J. BRANDMULleR, AND G. NONNENMACHER, Z. Elektrochem. 64, 940-945 (1960).

7. J. H. S. Green, W. Kynaston, AND H. M. Paisley, J. Chem. Soc. 473-478 (1963).

8. P. N. Gates, K. RadClifFe, AND D. Steele, Spectrochim. Acta Part $\boldsymbol{A}$ 25, 507-516 (1969).

9. J. V. Shukla, K. N. Upadhya, And D. K. RaI, Indian J. Pure Appl. Phys. 9, 815-819 (1971).

10. R. L. ZIMMERMAN AND T. M. DUNN, to be published. 
11. M. S. Robey and E. W. SchlaG, J. Chem. Phys. 30, 9-12 (1978).

12. C. Guttman And S. A. Rice, J. Chem. Phys. 61, 661-665 (1974).

13. L. J. VolK AND E. K. C. LeE, J. Chem. Phys. 67, 236-241 (1977).

14. L. J. VolK AND E. K. C. LeE, J. Chem. Phys. 67, 242-246 (1977).

15. D. Phillips, M. G. Rockiey, AND M. D. Swords, Chem. Phys. 38, 301-312 (1979).

16. R. A. Coveleski, D. A. Dolson, and C. S. Parmenter, J. Chem. Phys. 72, 5774-5775 (1980).

17. N. Halberstadt and A. Tramer, $J$. Chem. Phys. 73, 6343-6344 (1980).

18. W. D. Lawrance and A. E. W. KniGht, J. Chem. Phys. 77, 570-571 (1982).

19. S. H. Kable, W. D. Lawrance, and A. E. W. KNIGHT, J. Chem. Phys. 86, 1244-1247 (1982).

20. J. D. SPANGleR AND H. SPONER, Spectrochim. Acta 19, 169-187 (1963).

21. J. D. SPANGleR AND H. SPONER, J. Chem. Phys. 48, 698-714 (1968).

22. A. H. Francis AND C. B. HaRRIS, J. Chem. Phys. 57, 1050-1065 (1972).

23. G. Kothandaraman and D. S. Tinti, Chem. Phys. Lett. 19, 225-230 (1973).

24. M. J. Buckley, C. B. HARris, AND R. M. PANos, J. Amer. Chem. Soc. 94, 3692-3699 (1972). 